\title{
Génesis del deseo y su objeto: consideraciones a partir de la clínica y la literatura
}

\author{
The origins of desire and its object: insights based on clinical praxis and literature \\ Jesús Cisneros Herrera ${ }^{a}$
}

\begin{abstract}
:
Based on a clinical case and two literary works, the author analyses the rise of desire and the birth of its objetct as a two-faced phenomenon, where drives and psychic structuring converge. Firs case comes from a clinical work with and male adult who experiences sexual attraction to boys and male preadolescents. Second case, comes from the novel Lolita by Vladimir Nabokov, which deals with a 40-years-old man who experiences sexual attraction to "nymphes", special girls between 9 and 14 years old. The last case comes from the novel The Tunnel, by Ernesto Sábato, which deals with a painter who falls in love with a woman touch by one a his pictures. Each case poses a different way through which drives find their way out and an object of desired is created.
\end{abstract}

Keywords:

Drives, desire, object, psychoanalysis

\begin{abstract}
Resumen:
Con base en un caso clínica y en dos obras literarias, el autor analiza el surgimiento del deseo y la creación de su objeto como un fenómeno de dos caras, en el que las pulsiones y la estructuración psíquica convergen. El primer caso proviene de un trabajo clínico con un adulto varón que experimentaba atracción sexual por niños y prepúberes varones. El segundo caso proviene de la novel Lolita de Vladimir Nabokov, en la que un hombre de 40 años de edad experimente atracción sexual por las "nínfulas", niñas especiales entre 9 y 14 años de edad. El último caso provine de la novel El túnel de Ernesto Sábato, la cual narra la historia de un pintor que se enamora de una mujer conmovida por uno de sus cuadros. Cada uno plantea un camino distinto por el cual las pulsiones son descargadas y se crea un objeto de deseo.
\end{abstract}

Palabras Clave:

Pulsiones, deseo, objeto, psicoanálisis

\section{Introducción}

Una de las grandes rupturas que operó la teoría freudiana a principios del siglo XX fue la que separa el terreno de lo biológico y el de lo psíquico a nivel epistemológico, aun cuando no siempre se haya reconocido su alcance. Los conceptos de instinto y pulsión ilustran esta ruptura; el primero es un componente biológico predeterminado en su funcionamiento que, a base de experiencias en las que un placer carente de valor para la supervivencia del organismo, se desnaturaliza, por así decirlo, para dar paso a la pulsión (1). Ésta no tiene un camino ni un destino predeterminados, sino que es una fuerza que puede recorrer cualquier camino para llegar a cualquier destino posible. El destino de la pulsión es un objeto -en sentido psicoanalítico- en el que se satisface.

A pesar de diferenciarse del instinto, la pulsión (2) sigue teniendo su origen en los procesos corporales que se transfiguran en una fuerza psíquica que puede dirigirse hacia cualquier objetivo imaginable. Green (3) señala la contradicción contenida en los asertos freudianos. Por un lado, el objeto que satisface a la pulsión es el más versátil de sus componentes (2); por otro, la melancolía se caracteriza por la fijación de la libido, es decir, de la pulsión, en un objeto único y perdido (4). En realidad, estos hechos sólo son contradictorios si se mezclan dos planos, el de lo general y el de lo particular. Es decir, la versatilidad a la que se refiere Freud atañe a la pulsión como concepto abstracto presente en todos los individuos que explica por qué los objetos pulsionales son tan diferentes entre ellos, los individuos. Sin embargo, una vez que cada sujeto encuentra el objeto que satisface sus exigencias pulsionales, éste se rigidiza en mayor o menor medida, de modo que su pérdida supone sufrimiento.

En el plano fenomenológico, lo que observamos es un sujeto que se esfuerza por obtener un objeto, apropiarse de él u obtener su consentimiento para llevar a cabo la acción mediante la cual se descarga la tensión 
acumulada, la pulsión. El modo de proceder del sujeto para alcanzar su meta da cuenta de una compleja trama en la que se articulan las pulsiones entre sí y con la actividad del yo y las instancias superiores, es decir, en qué medida la satisfacción pulsional se consigue a costa de dañar o destruir el objeto -o incluso si en estas consecuencias para el objeto radica la verdadera satisfacción- o en qué medida la satisfacción sólo se obtiene si las acciones respetan ciertos códigos morales o ideales. La apropiación subjetiva de las mociones pulsionales, su registro en el nivel simbólico, constituyen el deseo. Dado que el universo de objetos de deseo es tan vasto, surge la pregunta ¿cómo un objeto del mundo deviene objeto de deseo?

En la teoría freudiana $(5,6)$, el sujeto está habitado por deseos inconscientes que a veces encuentran una desfiguración que les permite sortear la represión y hacerse presentes en la conciencia. Sueño, síntoma y actos fallidos se forman a partir de esos deseos inconscientes a modo de satisfacción parcial. La interpretación de estas formaciones de lo inconsciente busca establecer nexos entre ellas y lo reprimido, como si construyera puentes por donde la energía pulsional puede circular para encontrar un mejor modo de satisfacción. En este nuevo modo, el yo puede intervenir directamente sobre este proceso para obtener mejores resultados no sólo en términos de satisfacción pulsional, sino también de narcisismo. Entonces, la energía destinada a reprimir la pulsión se puede aprovechar para otras cosas, como encontrar satisfacciones.

Para conocer el origen del deseo, es necesario remontarnos a los orígenes de la vida pulsional. Ésta surge del encuentro del bebé con la madre, quien a través de los cuidados ofrece al niño un placer extra además de la satisfacción de necesidades. Dicho placer proviene del contacto de la boca del bebé con el pezón materno, principalmente, acompañado de otros estímulos, como caricias, besos y palabras amorosas que paulatinamente cobrarán preponderancia. Este proceso se ha denominado seducción originaria (7) o pulsación materna (8).

La conformación de la tópica psíquica requiere de la instalación de barreras a la satisfacción directa e inmediata de la pulsión. Estas barreras aparecen en la vida del niño como prohibiciones sucesivas a las distintas satisfacciones pulsionales -destete, control de esfínteres, amenaza de castración- que culminan con la disolución del complejo de Edipo. Las prohibiciones obligan al aparato psíquico, por un lado, a la renuncia de los objetos de satisfacción primarios, y, por otro, a abrir nuevos caminos para la pulsión y nuevos objetos que sean aceptables en la cultura, lo que Freud denominó sublimación. En algunos casos, la pulsión queda ligada a representaciones reprimidas y sólo puede acceder a lo consciente a condición de ligarse a otras representaciones, que enmascaran a las primeras. Así surgen los síntomas.

Una vez que el yo se forma y se hace cargo de la actividad psíquica, se asume como la entidad que desea ignorando los objetos originarios inconscientes reprimidos de la pulsión. La forma consciente de los deseos se articula en la actividad del yo, quien se encargará de mostrarlos u ocultarlos, satisfacerlos en la realidad o la fantasía y lidiar con los conflictos entre distintos deseos, o entre éstos y los imperativos morales. El yo no sólo hereda los deseos originarios o sus variaciones, sino que articula deseo nuevos con base en su historia libidinal, en los huellas de los objetos perdidos y en su propia capacidad de simbolizar y significar su experiencia. El grado en que los deseos inconscientes se repiten de forma disfrazada en los deseos del yo o en que constituyen una creación original, una neogénesis (8), depende de la fijeza y fuerza de las pulsiones y de la capacidad de elaboración del yo.

En este ensayo, me propongo explorar este último proceso, el de la génesis del deseo y de su objeto, a partir de un caso clínico y dos obras literarias en las que el yo, más que ser el sujeto deseante, es dominado por el deseo y la vida se organiza en función de obtener el objeto que lo satisface. El objetivo es entender el modo en que deseo y objeto se constituyen en la subjetividad.

\section{Fantasías homosexuales pedófilas}

De Masi (9) presenta el caso de Michael, hombre de 30 años de edad que experimentan atracción sexual por niños y prepúberes varones exclusivamente. Esa atracción se ha traducido en fantasías, pero nunca en actos. Los datos que aporta el autor acerca de Michael son los siguientes. Desde la infancia temprana, tenía fantasías sadomasoquistas -sumisión, daño, dolormediante las cuales podía alcanzar un orgasmo mental. Desde entonces empezó a sentir atracción por niños de su edad. Nunca ha tenido una relación real, y en dos ocasiones en que tuvo la oportunidad resultó ser impotente. A los 25 años de edad, intentó seducir a su hermano preadolecente y se enamoró de un vecino de 10 años de edad. Entre sus hermanos, tuvo una relación privilegiada con su madre durante su infancia, pero en la adolescencia se deterioró esa relación, cuando ella, también atraída por el mundo adolescente, estableció un vínculo idealizado con un amigo de Michael, al cual él mismo consideraba apuesto. Desde entonces, lleno de rencor, Michael se distanció de su madre. Al mismo tiempo, el padre había intentado educarlo con métodos autoritarios colocándolo en una posición de sumisión y rebeldía permeada por miedo y angustias de persecución. En la actualidad, Michael tiene un trabajo, 
pero sin contacto significativo con otros adultos. Su trabajo y su esparcimiento implican el contacto directo con grupos de niños varones, objeto de sus fantasías.

Se puede apreciar en Michael una tremenda inhibición de la vida pulsional, contenida casi en su totalidad en el plano de la fantasía. Esta situación comenzó desde su infancia temprana, según relata De Masi. El contenido de las fantasías indica un entrelazamiento irrompible entre pulsiones sexuales y de destrucción, incontrolable para el yo fuera de la fantasía. En las teorías sexuales infantiles (10), la actividad sexual aparece como violenta a causa de los sonidos que la acompañan. La escena primaria fue reforzada por el trato autoritario del padre, de modo que la angustia de persecución estuvo matizada por excitación sexual. De ese modo, la relación sádicomasoquista homosexual resultó privilegiada. La elección de niños y prepúberes como objeto de deseo es resultado, por un lado, de la intensidad del placer experimentado por medio de la fantasía en ese periodo de la vida de Michael y, por otro, de la identificación (4) con su madre, fascinada por el mundo adolescente, en especial por el amigo de Michael. Desplazado del lugar privilegiado en las preferencias maternas, Michael se aleja rencoroso de ella, pero resarce esa pérdida introyectando la capacidad imaginaria materna de determinar quién es el falo, quién es aquel que puede colmar sus deseos. Michael ejerce esa capacidad, al igual que el resto de su vida sexual, en el terreno de la fantasía, donde nada puede frustrarlo, cuestionarlo ni contradecirlo. Las prohibiciones sociales ofrecen a Michael la coartada para mantener sus inhibiciones.

\section{Humbert Humbert en Lolita}

Nabokov (11), por medio del deseo de su personaje Humbert Humbert, creó la figura icónica de Lolita. Lo único que sabemos de su infancia es: "mi madre, muy fotogénica, murió a causa de un absurdo accidente (un rayo durante un picnic) cuando yo tenía tres años" (p. 16); ningún otro indicio acerca de esta pérdida, de modo que parece un dato anecdótico intrascendente. Luego estuvo al cuidado de la hermana mayor de su madre, quien murió cuando él tenía dieciséis años, tal como ella misma lo había profetizado. Tampoco hay rastros de un duelo, ni patológico ni normal. Humbert destaca de esa tía la rigidez de sus normas. Su infancia transcurrió entre libros, su padre le leía; "yo le adoraba y le respetaba y me enorgullecía de él cuando llegaban hasta mí los comentarios de los criados sobre sus numerosas amigas, seres hermosos y afectuosos que me festejaban mucho y vertían preciosas lágrimas sobre mi alegre orfandad" ( $p$. 17). La descripción de su infancia es tranquila, con predominio de las actividades intelectuales sobre la vida pulsional. A los trece años conoció a Annabel, apenas unos meses menor que él. Además de ser encantadora, ella compartía con él el mismo intenso dolor que les causaba la dulzura y la indefensión de las crías de los animales. "Nos enamoramos inmediatamente, de una manera frenética, impúdica, angustiada" (p. 19); sin embargo, la vigilancia de los padres de ella y la tía de él, les impidieron consumar su amor. La tensión sexual se acumuló en ellos, pero apenas unos leves roces fue lo más que consiguieron, excepto por un encuentro en la playa y otro en su última noche juntos, en la que se besaron y acariciaron sus genitales, pero fueron interrumpidos en ambas ocasiones sin alcanzar la satisfacción plena deseada. Humbert describe una afinidad absoluta con Annabel, no sólo en el plano de la atracción física, sino en el de las ideas y los sentimientos. Cuatro meses después, ella murió. "Mucho después de su muerte, sentía que sus pensamientos flotaban a través de los míos. Antes de conocernos ya habíamos tenido los mismos sueños" (p. 21).

De ahí en adelante, no tuvo más experiencias amorosas, pues su deseo seguía ligado a Annabel. Sin embargo, en la novela tampoco hay referencias a procesos de duelo ante la pérdida de aquella niña; por el contrario, su presencia es aun mayor en la mente de Humbert después de morir. En el resto de su adolescencia, no sólo no tuvo otras experiencias amorosas, sino que tampoco sintió atracción por alguien más. Sin embargo, al convertirse en un adulto joven descubre/crea a las nínfulas: "muchachas entre los nueve y catorce años de edad, que revelan su verdadera naturaleza, que no es la humana, sino la de las ninfas (es decir, demoníaca)" (p. 24). Humbert desarrolla toda una teoría acerca de las nínfulas, en la que él mismo es especial por ser capaz de distinguirlas entre el resto de las niñas de su edad. En esta fabulación, Annabel se erige como el modelo primigenio de la nínfula. Es de notarse que este deseo aparece sólo para cuando su satisfacción es ilícita, cuando las normas sociales la prohíben, cuando debe ocultarse a los demás. A pesar de tener a su disposición mujeres hermosas de su edad, "me consumía un horno infernal de reconcentrada lujuria por cada nínfula que encontraba, pero a la cual no me atrevía a acercarme, pues era un pusilánime respetuoso de la ley" (p. 26). Humbert buscaba la manera de estar en lugares en los que había nínfulas para nutrir sus fantasías. "La más débil de las fantasías que conducían a mis poluciones era mil veces más deslumbrante que cualquier adulterio imaginado por el escritor de genio más viril o por el impotente más talentoso" (p. 26).

En Humbert Humbert, Ilama la atención la indiferencia, al menos aparente, hacia la pérdida de su madre y de su tía. La pérdida de Annabel tiene una clara importancia, pero tampoco hay indicios de un trabajo de duelo. El encuentro con Annabel revela una vida pulsional intensa, la cual presupone a una madre con la cual el bebé experimenta 
la seducción originaria o la pulsación materna, como se mencionó antes. Por ello, se puede inferir que la madre de Hubert cumplió con esa función. Sin embargo, queda la pregunta ¿por qué no hay indicios de sufrimiento por la muerte de la madre? Una disociación de la experiencia emocional de la pérdida en la época en que murió la madre o en un momento posterior de la historización del sujeto podría explicar la impasividad de Humbert adulto. A diferencia del caso de Michael (De Grasi), Humbert parece haber vivido una etapa de latencia muy prolongada que le permitió alcanzar un notable desarrollo intelectual. Sin embargo, el empuje pulsional de la adolescencia hace una súbita aparición cuando Humbert conoce a Annabel. En su historia libidinal, Annabel no se inserta en ninguna cadena de objetos; no hay antecedentes. $\mathrm{Y}$ en cierto sentido, tampoco habrá sucesores. El deseo despertado por Annabel es vivido de manera furtiva; aunque compartido con ella, la vigilancia de los adultos prohíbe el cumplimiento de ese deseo. Paradójicamente, la prohibición, la ley, termina por formar parte esencial de este triángulo, al grado de que Humbert esperó, para volver a tener deseos, el tiempo necesario para que estos estuvieran coartados por la ley.

La defensa de Humbert contra la pérdida es la escisión del yo (Freud). Aunque a nivel intelectual sabe que ha perdido un ser amado, a nivel afectivo no lo registra, por lo tanto no hay sufrimiento ni necesidad del trabajo de duelo. Las pulsiones sexuales se manifiestan sólo ante Annabel, y las prohibiciones hacen que la tensión aumente todavía más. A partir de entonces, la prohibición parece convertirse en catalizador del deseo, por lo que hasta alcanzar a mayoría de edad, Humbert vuelve a experimentar el deseo sexual fijado en quienes comparten las características ninfulares de Annabel. El deseo de Humbert se sitúa en un tiempo congelado en el que Lolita aparece como una advocación de Annabel que largos años de espera han hecho más deseable para Humbert, quien a diferencia del su deseo sí registra el paso del tiempo. El trágico final de la novela se debe a que, por primera vez, Humbert tiene la experiencia emocional de la pérdida, pero sin la capacidad de elaborarla.

\section{Juan Pablo Castel en El túnel}

Ernesto Sábato (12) creó la historia del pintor Juan Pablo Castel, quien cuenta su historia, al igual que Humbert Humbert, desde la prisión. Castel había sido condenado por matar a María Iribarne Hunter, de quien estaba profundamente enamorado y quien estaba casada. La conoció en una exposición de sus obras. Uno de sus cuadros, llamado Maternidad, presentaba en primer plano a una mujer que miraba jugar a un niño, mientras que en la parte superior izquierda, a través de una ventanita, se veía "una playa solitaria y una mujer que miraba el mar. Era una mujer que miraba como esperando algo, quizá algún llamado apagado y triste. La escena sugería, en mi opinión, una soledad ansiosa y absoluta". Castel observa cómo este detalle pasa desapercibido para todos los espectadores excepto para una muchacha que parece prestar atención "aislada del mundo entero" a la escena de la ventanita. Él sintió una enorme ansiedad en ese momento, y cuando ella desapareció entre la gente "yo vacilaba entre un miedo invencible y un angustioso deseo de llamarla. ¿Miedo de qué? Quizá, algo así como miedo de jugar todo el dinero de que se dispone en la vida a un solo número". Ese fugaz encuentro bastó para que el deseo de Castel quedara fijado en esa mujer. Durante meses, busco a la mujer pensando que entre ellos había una afinidad profunda y única. Cuando al fin la encontró, y le pregunto por "la ventanita", ella, turbada, no entendió la pregunta, lo cual decepcionó a Castel y se marchó. Si no había esa afinidad que él había imaginado, su interés por la mujer se desvanecería. Castel se retiró diciendo que había cometido una equivocación. Ella lo tuvo que alcanzar para explicar que su turbación le impidió entender su pregunta y aclararle que recordaba "constantemente" la escena de la ventanita. Luego, ella se retira corriendo y él siente que es ridículo y, sobre todo, innecesario ir tras ella, pues sabía a dónde se dirigía. Sin embargo, no resultan las cosas como lo esperaba y no la encuentra más ese día, por lo que "volví a casa en un estado de profunda depresión". "Mi corazón latía con violencia y sentí que se me abría una oscura pero vasta y poderosa perspectiva; intuí que una gran fuerza, hasta ese momento dormida, se desencadenaría en mí". Sin embargo, al otro día la encuentra; ella le dice que quisiera volver a huir de él, pero él responde "Prométame que no se irá nunca más. La necesito, la necesito mucho". Castel no sabe decir para qué la necesita, "siento que usted será algo esencial para lo que tengo que hacer, aunque todavía no me doy cuenta de la razón... Por lo pronto sé que es algo vinculado a la escena de la ventana: usted ha sido la única persona que le ha dado importancia". En el razonamiento de Castel, María ha visto ese detalle de su cuadro porque "usted piensa como yo... Mejor podría decirle que usted siente como yo. Usted miraba aquella escena como la habría podido mirar yo en su lugar". La comunión que hay en su mirada al cuadro se construye en el diálogo: "A veces creo que nada tiene sentido. En un planeta minúsculo, que corre hacia la nada desde millones de años, nacemos en medio de dolores, crecemos, luchamos, nos enfermamos, sufrimos, hacemos sufrir, gritamos, morimos, mueren y otros están naciendo para volver a empezar la comedia inútil", dice 
Castel. “¿Un mensaje de desesperanza, quizá?”, pregunta ella. "Sí", responde Castel.

En este caso, Sábato no ofrece antecedentes biográficos de Castel; sólo sabemos que era un hombre profundamente aislado de los demás. Lo demás, habrá que buscarlo en la situación y en el propio cuadro. La razón que aduce Castel para buscar a María es que ella piensa y siente como él. Lo que lo separa del mundo son las diferencias con los demás, la incapacidad para tolerar la alteridad, y parte de esa alteridad tal vez sea la posibilidad de vivir en un mundo sin sentido sin darse cuenta justo de esa falta de sentido. Entonces llega María y observa a la mujer del cuadro que mira al mar, tal vez con la misma soledad ansiosa y absoluta de la mujer del cuadro. Tanto para Castel, como para María, ella es la mujer de la escena de la ventanita; por ello, necesitará a María con más intensidad aun de la que lo impulsó a dibujar dicha escena. El deseo de Castel por María es un deseo de fusión.

No hay que olvidar que el nombre del cuadro es Maternidad, título que podría referirse a la mujer que mira al niño jugar o a la que observa al mar, o a ambas. La dulzura de ver al hijo jugar, o la incertidumbre por el destino del hijo que está por llegar o que ya se ha marchado, pero que en todo caso la madre experimenta en absoluta soledad. María captura ese fantasma de Castel, junto con su deseo.

\section{Disusión}

Green (3) rescata una frase de Freud: "en el camino que va de la fuente a la meta, la pulsión adquiere eficacia psíquica” (13). Green explica, "eficacia psíquica quiere decir estimular los recursos [...] de una actividad de significación" (3). La pulsión es un concepto que se encuentra en el límite entre lo somático y lo psíquico (2). Si bien nace de procesos corporales, de inmediato se inscribe en la actividad psíquica, cuya función será dar cauce a la energía pulsional valiéndose de sus sistemas de representación, el pensamiento y las posibilidades de acción. Pero la pulsión no piensa, sólo es una especie de fuerza ciega que el yo debe dirigir hacia algún lado o simplemente contenerla.

En cualquier caso, la pulsión exige un trabajo al yo, necesario para su existencia y su complejización. El recorrido de la pulsión por las representaciones que pueblan el espacio psíquico crea nuevos significados que se conjugan con la aparición en el mundo externo de lo que, a posteriori, será el objeto de deseo. No basta con que exista en la realidad, sino que se construya en lo interior como aquello que satisfará la pulsión. Desde esta perspectiva, se puede apreciar el enorme acierto de Winnicott (14) cuando, refiriéndose al objeto transicional, dijo que no había que preguntarse si el niño creó al objeto o si sólo lo encontró, porque ambas cosas son ciertas. Desde el punto de vista de la pulsión, no hay objetos correctos o incorrectos; la única distinción válida es si pueden satisfacerla o no. Niños y prepúberes, como en el caso de Michael, nínfulas entre 9 y 14 años de edad, como en el de Humbert, o una mujer casada, como en el de Castel, son los objetos exclusivos en los que se puede producir la descarga pulsional. Dado que la pulsión no tiene valor de supervivencia biológica, cualquiera de ellos es igual de apto.

Sin embargo, desde el punto de vista social, los objetos sí pueden calificarse como lícitos e ilícitos dependiendo de que se violen o no leyes al emplearlos como objetos de satisfacción pulsional. En estos tres casos, el objeto elegido es ilícito, y en Humbert este carácter quizá tiene un papel estructural en la elección de objeto: la prohibición como elemento esencial de la compulsión a la repetición humbertiana, que se refuerza por la renegación de la pérdida y la incapacidad de elaborar el duelo concomitante.

Desde el punto de vista de la complejización del yo, también se puede juzgar el objeto como enriquecedor o empobrecedor. La elección de niños o adolescentes tempranos como objeto de deseo va de la mano de la fantasía de posesión y dominio omnipotente, los cuales mantienen al yo libre de cuestionamientos y exigencias que lo obligarían a reconocer sus carencias y esforzarse por cambiar. La imposibilidad de renunciar a la posesión absoluta de María lleva a Castel a matarla.

En los tres casos, hay una carga pulsional acumulada que hace girar la vida del sujeto en torno al objeto de deseo, creado/encontrado por caminos muy diversos. La historia del sujeto con sus objetos primarios constituye la base sobre la que el sujeto edifica el objeto de deseo. La madre es el elemento esencial por su función sexualizante, pulsante, mientras que el padre, retomando a Lacan, se manifiesta en el papel que la ley juega en la relación del sujeto con su objeto.

\section{Referencias}

1. Laplanche J. Vida y muerte en psicoanálisis. Buenos Aires, Argentina: Amorrortu; 1970.

2. Freud S. Pulsiones y destinos de pulsión. En: Obras completas. Buenos Aires, Argentina: Amorrortu; 1915.

3. Green A. El pensamiento clínico. Buenos Aires, Argentina: Amorrortu; 2010.

4. Freud S. Duelo y melancolía. En: Obras completas. Buenos Aires, Argentina: Amorrortu; 1915.

5. Freud S. La interpretación de los sueños. En: Obras completas. Buenos Aires, Argentina: Amorrortu; 1900.

6. Freud S. Tres ensayos de teoría sexual. En: Obras completas. Buenos Aires, Argentina: Amorrortu; 1905. p. 108-210. 
7. Laplanche J. La prioridad del otro en psicoanálisis. Buenos Aires, Argentina: Amorrortu; 1992.

8. Bleichmar S. Clínica psicoanalítica y neogénesis. Buenos Aires, Argentina: Amorrortu; 1999.

9. De Masi F. The paedophile and his inner world: Theoretical and clinical considerations on the analysis of a patient. Int J Psychoanal. 2007;88:147-65.

10. Freud S. Sobre las teorías sexuales infantiles. En: Obras completas. Buenos Aires, Argentina: Amorrortu; 1908.

11. Nabokov V. Lolita. 4. ${ }^{a}$ ed. Barcelona, España: Anagrama; 2005. 389 p.

12. Sábato E. El túnel [Internet]. Disponible en: http://biblio3.url.edu.gt/Libros/sabato/tunel.pdf

13. Freud S. Nuevas conferencias de introducción al psicoanálisis. En: Obras completas. Buenos Aires, Argentina: Amorrortu; 1933.

14. Winnicott DW. Realidad y juego. Barcelona, España: Gedisa; 2006. 